\title{
Conversion of Mixed Waste of Wood and Plastic to Clean Fuels Using Pyrolysis in Nigeria - Numerical Study
}

\author{
Andrew N. Aziz ${ }^{1,3 *}$, Saad Mahmoud ${ }^{1}$, Raya Al-Dadah', Surindar Dhesi², Irina Kuznetsova², Cyril \\ Effiong $^{2}$, Ejikeme Kanu ${ }^{2}$ \\ ${ }^{1}$ School of Engineering, University of Birmingham, Edgbaston, Birmingham, B15-2TT \\ ${ }^{2}$ School of Geography, Earth and Environmental Sciences, University of Birmingham, Edgbaston, \\ Birmingham, B15-2TT \\ ${ }^{3}$ City of Scientific Research and Technological Applications, SRTA-City, New Borg El Arab City, 21934 \\ Alexandria, Egypt \\ ANM900@student.bham.ac.uk; S.M.MAHMOUD@ bham.ac.uk; \\ R.K.AL-DADAH@bham.ac.uk; S.K.DHESI@bham.ac.uk; I.KUZNETSOVA@bham.ac.uk; \\ CXE921@student.bham.ac.uk; EJK899@student.bham.ac.uk
}

\begin{abstract}
Waste management is a major challenge in Nigeria, where around 32 million tons of waste is generated annually including 13 million tonnes of agricultural waste and 2.5 million tons of plastic waste. Currently, the waste management system is very inefficient where almost $70 \%$ of the waste ends up in landfills, sewers, beaches and water bodies causing serious environmental and health problems. This work numerically investigates the conversion of mixed wastes (wood and plastics) to produce clean and affordable solid, liquid and gaseous fuels that can be used for cooking, heating and electricity generation.

Pyrolysis process which involves heating the waste at different rates in the absence of Oxygen has received significant research interest since it can convert various types of waste to clean fuels thus reducing fossil fuel consumption and $\mathrm{CO} 2$ emission. For example, wood waste can be converted to high-quality syngas, oil, and char while plastic waste can be converted to high-quality syngas, oil, light and heavy waxes. Also, it generates lower emissions compared to other waste conversion processes such as combustion, gasification, and plasma treatment.

In this study, a numerical model is developed to simulate the pyrolysis process of mixed wood and plastic waste materials to predict the outputs in terms of char, syngas, oil and wax production. The model is based on the kinetics of the reactions associated with wood and plastic when subjected to different heating rates from 320 to 923 Kelvin for 20 minutes. Results showed that for $1 \mathrm{~kg}$ of mixed waste (30\% plastic and 70\% wood) and after 20 minutes of heating, the output consists of 50.13\% syngas, $8.35 \%$ oil, $9.5 \%$ char, $10.8 \%$ light Wax and $8.33 \%$ heavy wax. This modelling allows for controlling the output composition based on varying the input waste constituents which can optimize the waste conversion process.
\end{abstract}

Keywords: Pyrolysis, Mixed Waste, Modelling, Clean energy.

\section{Introduction}

Nigeria is a developing agricultural country which generates huge amount of agricultural waste reaching 13 million tonnes per year where significant amounts of this waste are either left to rot or burned in open fields causing significant air pollution [1]. The most common agricultural wastes are maize cobs, husks, and stalks (62.5 percent) and cassava stalks and peels 60 percent[2]. Also, in urban cities there is an increasing amount of waste with heavy plastic of around 2.5 tons of plastic waste per year [3]. Currently, the waste management system is very inefficient where almost $70 \%$ of the waste ends up in landfills, sewers, beaches and water bodies causing serious environmental and health problems[4].

Pyrolysis has been developed since the 1970s [5] which is an advanced thermochemical conversion process of carbonic feedstock in the absence of oxygen to produce bio-fuel (oil, char, and fuel gases) [6]. This process can reduce greenhouse gas emissions and contribute to energy security. There are three types of pyrolysis [7]. Slow pyrolysis: this is the slow heating rate process between $(5-7 \mathrm{~K} / \mathrm{min})$ which mainly produce char and low liquid and gaseous products. Fast pyrolysis: in this process, the material heating rate is high $650 \mathrm{~K}$ for $5 \mathrm{~s}$ and it produces mainly liquid fuel. In the flash process, the material is briskly heated for few seconds or even less produce pyrolysis oil. The quality and the stability of the generated oil are influenced by the char or ash content of bio-oil. Various studies have been conducted to model the slow process of various wastes. Koufopanos et al. [8] established the kinetic model of the pyrolysis of biomass and its constituents to develop an 
efficient pyrolizer. Koufopanos and Papayannakos [9] studied the kinetics coupled with thermal and heat transfer effects and concluded that the pyrolysis can be applied for a wide range of heating rates $573 \mathrm{~K}$ to $873 \mathrm{~K}$ and particle sizes from $1 \mathrm{~mm}$ to $20 \mathrm{~mm}$. Kabir et al. [6] presented a numerical and experimental analysis about the pyrolysis of green waste process showing that around $19.972 \%$ bio-oil, $40.83 \%$ bio-char, and $29.77 \%$ syn-gas can be generated.. Miljković et. al [10] built a mathematical model of single-particle biomass under the pyrolysis process and compared the results with experimental measurements and other different types of wood samples, the ultimate analyses for the composition have been reported. Dubdub and Al-Yaari [11] investigated the kinetics of mixed plastic waste. Their results showed that using a single thermal degradation stage, the pyrolysis of pure polymer samples happens in the following order: PS, PP, LDPE, and HDPE. Andersen et al. [12] simulated the pyrolysis process of plastic waste to produce environmentally friendly fuel. The above literature indicates that most of the research was conducted on wood samples or plastic samples separately. Therefore, there is a need to develop models to simulate the pyrolysis process for converting mixed wastes to clean fuels. In this study, a numerical model for simulating the pyrolysis of mixed waste consisting of wood and plastic using the Ordinary Differential Equations (ODEs) solver in MATLAB to predict the outputs in terms of syngas, char, oil, light and heavy waxes.

\section{Model Description}

This model aims to simulate the pyrolysis process for converting heavy plastics and wood to clean fuels including syngas, oil and charcoal. It uses the kinetic equations of heavy plastic and wood subjected to different heating rates from $320 \mathrm{~K}$ to $923 \mathrm{~K}$. Eq. 1 to Eq. 8 represents the kinetic reactions for wood where Eq. 1 describes the initial concentration of wood. After applying the heat, the gas starts to be produced as shown in Eq. 2. At the same heating rate Eq. 3 reveals the amount of char produced from the same sample. Then during the second phase reaction, the same outputs occur as in Eq. 4 and Eq. 5. The auxiliary equations 6-8 are used to determine the values of the reaction constants related to the wood sample with Table 1 listing the required input parameters.

$$
\begin{gathered}
\frac{\partial C_{w}}{\partial t}=-\mathrm{k}_{w 1} \cdot\left(C_{w}\right)^{\mathrm{n} 1}-\mathrm{k}_{w 2} \cdot\left(C_{w}\right)^{\mathrm{n} 1} \\
\frac{\partial C_{\text {gas } 1}}{\partial t}=\mathrm{k}_{w 1} \cdot\left(C_{w}\right)^{\mathrm{n} 1}-\mathrm{k}_{w 3} \cdot\left(C_{\text {gas } 1}\right)^{\mathrm{n} 2} \cdot\left(C_{\text {char } 1}\right)^{\mathrm{n} 3} \\
\frac{\partial C_{\text {char } 1}}{\partial t}=\mathrm{k}_{w 2} \cdot\left(C_{w}\right)^{\mathrm{n} 1}-\mathrm{k}_{w 3} \cdot\left(C_{\text {gas } 1}\right)^{\mathrm{n} 2} \cdot\left(C_{\text {char } 1}\right)^{\mathrm{n} 3} \\
\frac{\partial C_{g a s 2}}{\partial t}= \\
\frac{\partial C_{\text {char } 1}}{\partial t}=\mathrm{k}_{w 3} \cdot\left(C_{\text {gas } 1}\right)^{\mathrm{n} 2} \cdot\left(C_{\text {char } 1}\right)^{\mathrm{n} 3} \\
\mathrm{k}_{w 1}=\mathrm{A}_{w 1} \cdot e^{\left(\frac{D_{1}}{T}+\frac{L_{1}}{T^{2}}\right)} \\
\mathrm{k}_{w 2}=\mathrm{A}_{w 2} \cdot e^{\left(\frac{D_{2}}{T}+\frac{L_{2}}{T^{2}}\right)} \\
\mathrm{k}_{w 3}=\mathrm{A}_{w 3} \cdot e^{\left(\frac{-E_{3}}{T \cdot R c}\right)}
\end{gathered}
$$

Where $C_{w}, C_{g a s}, C_{c h a r}$ are concentrations for Wood, gas, char respectively.

Eq. 9 to Eq. 13 represents the kinetic reactions for heavy plastics, where Eq. 9 represents the initial plastic concentration. After applying the heat, the light wax starts to form first which is represented in Eq. 10. At the same heating rate, Eq. 11 determines the amount of heavy wax produced from the same sample. Then, Eq.12 gives the oil production while Eq.13 determines the amount of the produced gas. The values of the reaction constants related to the plastic sample at 713 Kelvin plastic are shown in table 2.

$$
\frac{\partial C_{p}}{\partial t}=-\mathrm{k}_{p 1} \cdot C_{p}-\mathrm{k}_{p 2} \cdot C_{p}-\mathrm{k}_{p 3} \cdot C_{p}-\mathrm{k}_{p 4} \cdot C_{p}
$$




$$
\begin{gathered}
\frac{\partial C_{L W}}{\partial t}=\mathrm{k}_{p 1} \cdot C_{p}-\mathrm{k}_{p 6} \cdot C_{L W}-\mathrm{k}_{p 5} \cdot C_{L W} \\
\frac{\partial C_{H W}}{\partial t}=\mathrm{k}_{p 4} \cdot C_{p}-\mathrm{k}_{p 8} \cdot C_{H W}-\mathrm{k}_{p 9} \cdot C_{H W} \\
\frac{\partial C_{o i l}}{\partial t}=\mathrm{k}_{p 2} \cdot C_{p}-\mathrm{k}_{p 5} \cdot C_{H W}-\mathrm{k}_{p 9} \cdot C_{H W}-\mathrm{k}_{p 7} \cdot C_{o i l} \\
\frac{\partial C_{p g a s}}{\partial t}=\mathrm{k}_{p 3} \cdot C_{p}-\mathrm{k}_{p 6} \cdot C_{L W}-\mathrm{k}_{p 7} \cdot C_{o i l}-\mathrm{k}_{p 8} \cdot C_{H W}
\end{gathered}
$$

\begin{tabular}{|c|l|}
\hline \multicolumn{2}{|c|}{ Table 1: Model inputs for wood. } \\
\hline Parameter name & value \\
\hline Wood density $\left(\rho_{0}\right)$ & $650\left[\mathrm{~kg} / \mathrm{m}^{3}\right]$ \\
\hline Reaction constant $\left(\mathrm{A}_{1}\right)$ & $9.973 \times 10-5[1 / \mathrm{s}]$ \\
\hline Reaction constant $\left(\mathrm{A}_{2}\right)$ & $1.068 \times 10-3[1 / \mathrm{s}]$ \\
\hline Reaction constant $\left(\mathrm{A}_{3}\right)$ & $5.7 \times 105[1 / \mathrm{s}]$ \\
\hline Reaction constant $\left(\mathrm{L}_{1}\right)$ & $-9061227 \mathrm{~K}^{2}$ \\
\hline Reaction constant $\left(\mathrm{L}_{2}\right)$ & $-6123081 \mathrm{~K}^{2}$ \\
\hline Activation energy $\left(\mathrm{E}_{3}\right)$ & $81000 \mathrm{~J} / \mathrm{mol})$ \\
\hline Reaction order $\left(\mathrm{n}_{1}\right)$ & 1 \\
\hline Reaction order $\left(\mathrm{n}_{2}\right)$ & 1.5 \\
\hline Reaction order $\left(\mathrm{n}_{3}\right)$ & 1.5 \\
\hline Applied Temperature range$(\mathrm{T})$ & {$[320: 923][\mathrm{Kalvin}]$} \\
\hline
\end{tabular}

\begin{tabular}{|c|l|}
\hline \multicolumn{2}{|c|}{ Table 2: Estimated rate constants at 713 Kelvin for plastic [13]. } \\
\hline Parameter name (The rate constants of the reactions) & value \\
\hline $\mathrm{k}_{p 1}$ & 0.170488 \\
\hline $\mathrm{k}_{p 2}$ & $2.43 \mathrm{E}-08$ \\
\hline $\mathrm{k}_{p 3}$ & 0.0301269 \\
\hline $\mathrm{k}_{p 4}$ & 0.206132 \\
\hline $\mathrm{k}_{p 5}$ & 0.0146288 \\
\hline $\mathrm{k}_{p 6}$ & 0.0103907 \\
\hline $\mathrm{k}_{p 7}$ & $2.25 \mathrm{E}-14$ \\
\hline $\mathrm{k}_{p 8}$ & 0.0204982 \\
\hline $\mathrm{k}_{p 9}$ & $3.48 \mathrm{E}-10$ \\
\hline
\end{tabular}

Figure 1 illustrates the structure of the pyrolysis for the mixed waste of heavy plastic and wood, while figure 2 shows the applied heat rates for this process.

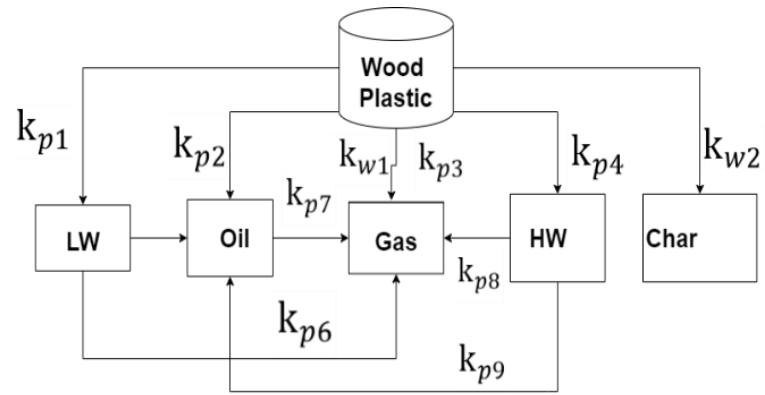

Fig. 1: Model structure. 


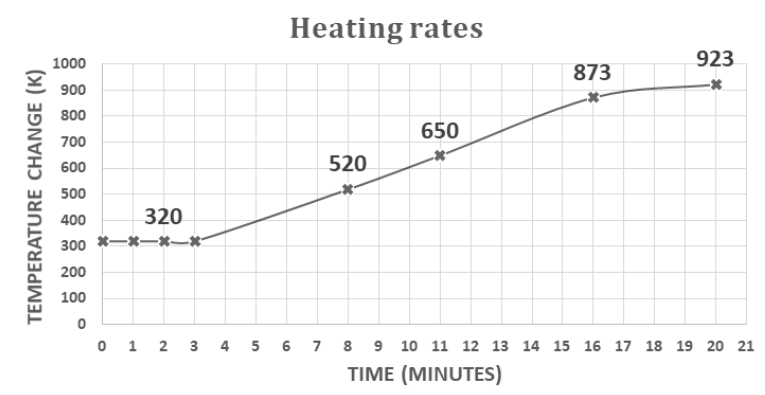

Fig. 2: Applied heating rates.

The total volume of gas generated from the pyrolysis of wood and heavy plastics by combining Eq. 2, Eq. 4, and Eq. 13 as shown in Eq. 14:

$$
\frac{\partial C_{W p g a s}}{\partial t}=\mathrm{k}_{w 1} \cdot\left(C_{w}\right)^{\mathrm{n} 1}+\mathrm{k}_{p 3} \cdot C_{p}-\mathrm{k}_{p 6} \cdot C_{L W}-\mathrm{k}_{p 7} \cdot C_{o i l}-\mathrm{k}_{p 8} \cdot C_{H W}
$$

Fig. 3 shows the model output in terms of the wood sample mass change with time as subjected the heating rate shown in Fig. 2 compared to the results of Miljkovi et. al. [10]. It can be seen that the model predicted the published experimental results with maximum error of $13.5 \%$.

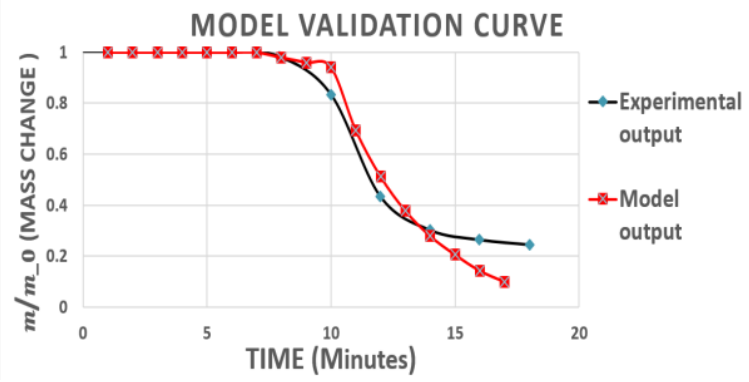

Fig. 3: Model validation with published experimental data.

\section{Results And Discussion}

Fig. 4 shows the percentage yield of the pyrolysis process of a mixed waste consisting of 300 grams of plastic and 700 grams wood using the heating rates shown in Fig. 2 for a period of 20 minutes. It can be seen that during the first 11 minutes, the wood showed no change in its behaviour, while the plastic started to degrade. Table 4 shows that using one $\mathrm{kg}$ of mixed waste composed of 300 grams plastic and 700 grams wood will produce $50.13 \%$ syngas, $8.35 \%$ oil, $9.5 \%$ char, $10.8 \%$ light Wax, and $8.33 \%$ heavy wax. Although light and heavy waxes are not fuels but they have other useful applications like their significance stems from the distinct properties that they impart to these formulations. Waxes, for example, can minimize the viscosity of a hot melt adhesive, add lustre to an ink or fruit coating emulsion, serve as a lubricant through the fabrication of PVC pipes, or impart desirable buff ability, gloss, and toughness properties to emulsion paste polish or a solvent., G. Webber[14]. 


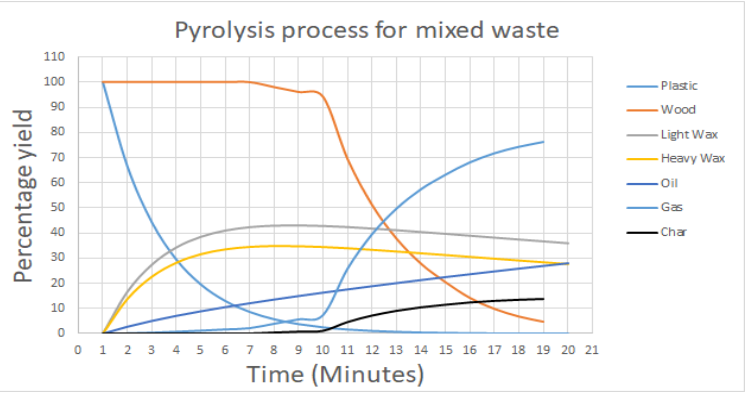

Fig. 4: Model output Time vs percentage yield.

\begin{tabular}{|l|c|c|c|c|}
\hline \multicolumn{5}{|c|}{ Table 4: Output analysis for mixed waste. } \\
\hline Plastic 300 grams & $\begin{array}{l}\text { Plastic outputs } \\
\text { grams }\end{array}$ & Wood 700 grams & $\begin{array}{l}\text { Wood outputs in } \\
\text { grams }\end{array}$ & 1000 grams (Mixed waste) \\
\hline LW=36.15\% & 108 & & & $10.8 \%$ \\
\hline HW=27.75\% & 83.25 & & & $8.33 \%$ \\
\hline Oil =27.82\% & 83.46 & Gas=68.19\% & 477.33 & $8.35 \%$ \\
\hline Gas=8.25\% & 24 & Char=13.55\% & 94.85 & $9.13 \%$ \\
\hline & \multicolumn{5}{|c}{} \\
\hline
\end{tabular}

\section{Conclusion}

Nigeria is an agricultural developing country with huge amount of waste including 13 million tonnes per year of agricultural waste where significant amounts of this waste are either left to rot or burned in open fields causing significant environmental damage. Also, in urban cities there is an increasing amount of waste where heavy plastic represents a significant amount. In this work, a numerical model for the pyrolysis process of mixed waste consisting of heavy plastic and wood was developed using MATLAB software and the built-in solver for ODEs to predict the amount of clean fuel produced in terms of syngas, oil and char. The results of the model using wood were compared to published results showing good agreement with maximum deviation of $13.5 \%$ Using one $\mathrm{kg}$ of mixed waste composed of 300 grams plastic and 700 grams wood, the model shows that $50.13 \%$ syngas, $8.35 \%$ oil, $9.5 \%$ char, $10.8 \%$ light Wax, and $8.33 \%$ heavy wax can be produced. Results also shows that mixed waste pyrolysis has the potential to manage the wood and plastic waste in Nigeria, improve the environment and generate clean fuels like syngas, oil and charcoal.

\section{Acknowledgements}

The authors would like to acknowledge the financial support from the Institute for Global innovation (IGI) and the Institute of Advanced Studies (IAS) of the University of Birmingham as part of the IGI/IAS Clean Air pump prime funding, project ID 4037.

\section{References}

[1] F. O. Olanrewaju, G. E. Andrews, H. Li, and H. N. Phylaktou, "Bioenergy potential in Nigeria," Chem. Eng. Trans., vol. 74, no. December 2018, pp. 61-66, 2019.

[2] F. O. Oladipo, O. D. Olorunfemi, O. D. Adetoro, and T. O. Oladele, "Farm waste utilization among farmers in Irepodun local government area, Kwara state, Nigeria: implication for extension education service delivery," Ruhuna J. Sci., vol. 8, no. 1, p. 1, 2017.

[3] I. Magoum, "NIGERIA: the FEC approves a new law on plastic waste management," Afrik21, 2020.

[4] O. O. Olanrewaju and D. Oyebade, "Environmental Menace of Plastic Waste in Nigeria: Challenges, Policies and Technological Efforts Plastic Recycling and Reusabiliy View project The project is on waste management View project," no. June, 2019.

[5] A. Bosmans and L. Helsen, "Energy From Waste: Review of Thermochemical Technologies for Refuse Derived Fuel (RDF) Treatment," Third Int. Symp. Energy from Biomass Waste, no. November 2010, pp. 8-11, 2010.

[6] M. J. Kabir, A. A. Chowdhury, and M. G. Rasul, "Pyrolysis of municipal green waste: A modelling, simulation and 
experimental analysis," Energies, vol. 8, no. 8, pp. 7522-7541, 2015.

[7] N. Canabarro, J. F. Soares, C. G. Anchieta, C. S. Kelling, and M. A. Mazutti, "Thermochemical processes for biofuels production from biomass," Sustain. Chem. Process., vol. 1, no. 1, p. 22, 2013.

[8] C. A. Koufopanos, A. Lucchesi, and G. Maschio, "Kinetic modelling of the pyrolysis of biomass and biomass components," Can. J. Chem. Eng., vol. 67, no. 1, pp. 75-84, 1989.

[9] C. A. Koufopanos, N. Papayannakos, G. Maschio, and A. Lucchesi, "Studies on Kinetics, Thermal and Heat Transfer Effects," Can. J. Chem. Eng., vol. 69, pp. 907-915, 1991.

[10] B. Miljković, B. Nikolovski, D. Mitrović, and J. Janevski, "Modeling for pyrolysis of solid biomass," Period. Polytech. Chem. Eng., vol. 64, no. 2, pp. 192-204, 2020.

[11] I. Dubdub and M. Al-Yaari, "Pyrolysis of mixed plastic waste: I. kinetic study," Materials (Basel)., vol. 13, no. 21, pp. $1-15,2020$.

[12] M. Andersen, K. A. Sætre, S. Fredriksen, and C. Pfeiffer, "Simulation of the Pyrolysis Process: from Plastic Waste to Environmental Friendly Fuel," Proc. 59th Conf. imulation Model. (SIMS 59), 26-28 Sept. 2018, Oslo Metrop. Univ. Norw., vol. 153, no. September, pp. 303-307, 2018.

[13] Y. Safadi, J. Zeaiter, and M. Ahmad, "Advanced Modeling of High Density Polyethylene Pyrolysis," Int. J. Therm. Environ. Eng., vol. 5, no. 2, pp. 123-128, 2013.

[14] G. V. Webber, "Wax Characterisation by Instrumental Analysis,” no. December, 2000. 